\title{
WALS Estimation and Forecasting in Factor-based Dynamic Models with an Application to Armenia
}

\author{
Karen Poghosyan andJan R. Magnus ${ }^{\circledR}$ \\ Central Bank of Armenia and Tilburg University
}

\begin{abstract}
Two model averaging approaches are used and compared in estimating and forecasting dynamic factor models, the well-known Bayesian model averaging (BMA) and the recently developed weighted average least squares (WALS). Both methods propose to combine frequentist estimators using Bayesian weights. We apply our framework to the Armenian economy using quarterly data from 2000-2010, and we estimate and forecast real GDP growth and inflation.
\end{abstract}

Key words: Dynamic Models, Factor Analysis, Model Averaging, Monte Carlo, Armenia JEL Classifications: C11, C13, C52, C53, E52, E58

\section{INTRODUCTION}

In the recent macroeconomic literature, factor-based dynamic models have become popular. The idea underlying these models is that, while there are potentially a very large number of explanatory variables, most of the movement in the dependent variable can be explained by only a few variables or linear combinations thereof. One of the reasons why this happens is that the explanatory variables are often highly correlated.

We mention three recent examples where this approach has been successfully applied. Stock and Watson (2002) performed forecasting experiments for USA macroeconomic variables using 215 explanatory variables. From this large number of variables they extracted a few factors to forecast key macroeconomic indicators. Forni et al. (2000, 2003) provided a timeseries forecasting method based on spectral analysis, and applied this method to forecast Euro-area industrial production and inflation using 447 explanatory variables. Finally, Bernanke et al. (2005) took a vector autoregressive (VAR) model and augmented it with factors based on 120 macroeconomic variables. All these papers find that the mean squared errors of estimates and forecasts based on factor models are lower than those obtained from vector autoregressive models.

After extracting factors, these models are typically estimated in the traditional econometric way, that is, separating model selection and estimation. Recent advances in econometric theory allow us to combine model selection and estimation into one procedure, thus avoiding the undesirable problem of pretesting. This procedure is called 'Bayesian model averaging'. The purpose of the current paper is to apply the basic (non-dynamic) model averaging

\footnotetext{
${ }^{\circledR}$ Karen Poghosyan, Central Bank of Armenia, Economic Research Department, Yerevan, Armenia, (email: kpoghosyan@cba.am).

Jan R. Magnus, Department of Econometrics \& Operations Research, Tilburg University, The Netherlands, (email: magnus@uvt.nl).

We are grateful to the editor and two anonymous referees for their constructive and helpful comments.
} 
framework to dynamics and factor extraction, and to use this dynamic framework to explain and forecast Armenian real GDP growth and inflation.

In addition, we wish to compare in this context the standard Bayesian model averaging (BMA) approach to the 'weighted average least squares' (WALS) approach, recently developed in Magnus et al. (2010). The WALS approach has both theoretical and computational advantages over BMA. Theoretical, because it generates bounded risk and contains an explicit treatment of ignorance; computational, because its computing time increases linearly rather than exponentially with the dimension of the model selection space. In Magnus et al. (2010), WALS was applied to growth empirics, but without dynamics or lagged dependent variables.

Estimation and forecasting in factor-based dynamic models using the BMA algorithm was first applied by Koop and Potter (2004) to US data. Our current paper follows their general approach, but also reports on experiments where the two model averaging methods (WALS and BMA) are compared.

The paper is organized as follows. The factor-based dynamic model is introduced in Section 2. In Section 3 we present the WALS and BMA model averaging methods. Some characteristics of Armenia are provided in Section 4, and the data are described in Section 5, which also contains a preliminary analysis of the data. The estimation results are given in Section 6. We report on two experiments. First, an estimation simulation in Section 7, then a forecast experiment in Section 8. Section 9 concludes.

\section{THE DYNAMIC FACTOR MODEL}

We consider the dynamic regression model

$$
y_{t}=\alpha(L) y_{t-1}+\beta(L) x_{t-1}+\xi_{t} \quad(t=1, \ldots, T)
$$

where $y_{t}$ is a scalar dependent variable, $x_{t}$ is a $k \times 1$ vector of nonrandom explanatory variables, $\alpha(L)$ and $\beta(L)$ are polynomials in the lag operator of dimensions $p_{1}$ and $p_{2}$, respectively, and $\xi_{t}$ is a random vector of unobservable disturbances, independently and identically distributed as $\mathrm{N}\left(0, \sigma^{2}\right)$.

We have $p_{1}+k p_{2}$ explanatory variables, which may be a large number. Moreover, many of the parameters may be close to zero. These two factors make it difficult to apply standard estimation methods (Koop and Potter, 2004). It is then common in the macro-econometric literature to replace the $k$ explanatory variables with a much smaller number of variables. This can be achieved by using principal component or factor analysis algorithms. Then, after extracting the principal components, Model (2.1) can be rewritten as

$$
y_{t}=\alpha(L) y_{t-1}+\gamma(L) f_{t-1}+\varepsilon_{t} \quad(t=1, \ldots, T)
$$

where $f_{t}(m \times 1)$ is the vector of extracted principal components and $\gamma(L)$ is a polynomial in the lag operator (Stock and Watson, 2002). We assume that $m<k$ and $m<T$. Of course, as noted by Koop and Potter (2004, p. 553), there is a cost in this type of transformation, namely that the interpretation of the variables is more difficult.

Koop and Potter (2004) were the first to show how Bayesian model averaging can be applied to estimation and forecasting using dynamic factor models. Their study applies BMA to the problem of forecasting GDP growth and inflation using quarterly US data on 162 time series. Our paper follows their approach, but also compares two competing estimation procedures: 
BMA and WALS. This will not only tell us something about the power of the two algorithms, but will also provide information about the robustness of our results.

\section{BAYESIAN COMBINATIONS OF FREQUENTIST ESTIMATORS}

The idea behind combining estimators (or forecasts) is to use information from all models within a given family in a continuous fashion. In contrast to standard econometrics - where one first selects a model and then estimates the parameters within the chosen model, a discrete procedure - we combine the estimates from all models considered, where some models get a higher weight than others, based on priors and diagnostics. One advantage of this procedure is that we avoid the well-known pretest problem: our procedure is a joint procedure, where model selection and estimation are combined.

As our framework we choose the linear regression model

$$
y=X_{1} \beta_{1}+X_{2} \beta_{2}+\varepsilon=X \beta+\varepsilon, \quad \varepsilon \sim \mathrm{N}\left(0, \sigma^{2} I_{n}\right),
$$

where $y(n \times 1)$ is the vector of observations, $X_{1}\left(n \times k_{1}\right)$ and $X_{2}\left(n \times k_{2}\right)$ are matrices of nonrandom regressors, $\varepsilon$ is a random vector of unobservable disturbances, and $\beta_{1}$ and $\beta_{2}$ are unknown parameters which we need to estimate. We assume that $k_{1} \geq 1, k_{2} \geq 0$, $k=k_{1}+k_{2} \leq n-1$, that $X=\left(X_{1}: X_{2}\right)$ has full column-rank, and that the disturbances are independent and identically distributed.

The reason for distinguishing between $X_{1}$ and $X_{2}$ is that $X_{1}$ contains variables that we want to be in the model (whatever $t$-values or other diagnostics we find), while $X_{2}$ contains variables that may or may not be in the model. The columns of $X_{1}$ are called 'focus' regressors, the columns of $X_{2}$ 'auxiliary' regressors. The uncertainty about each auxiliary regressor, that is whether we should or should not include the regressor in our model, is a very common situation, and the application of model averaging is then a natural procedure. Rather than choosing one model by preliminary diagnostic tests, we assume that each model tells us something of interest about our focus parameters. We do not, however, trust each model to the same degree, and the resulting weights are determined by priors and data. In this paper we concentrate on two model averaging algorithms, the well-known BMA algorithm and the recently introduced WALS algorithm. We briefly summarize each in turn. Full details and background references are provided in Magnus et al. (2010). The MATLAB codes can be obtained from www.janmagnus.nl/items/BMA.pdf, and the Stata codes are described in De Luca and Magnus (2011).

\subsection{Bayesian Model Averaging (BMA)}

With the exception of Magnus et al. (2010), the whole literature on Bayesian model averaging considers the case $k_{1}=1$. We summarize the approach of Magnus et al. (2010, Section 2). Since there are $k_{2}$ auxiliary regressors, we have $2^{k_{2}}$ different models to consider, because each auxiliary regressor can either be included or not. For each subset $X_{2 i}$ of $k_{2 i} \leq \mathrm{k}_{2}$ auxiliary variables we consider the regression

$$
y=X_{1} \beta_{1}+X_{2 i} \beta_{2 i}+\varepsilon_{i}
$$

which we call model $\mathcal{M}_{i}$. If we let $p\left(\mathcal{M}_{i}\right)$ denote the prior probability that $\mathcal{M}_{i}$ is the true model, then the posterior probability for model $\mathcal{M}_{i}$ is given by

$$
\lambda_{i}=p\left(\mathscr{M}_{i} \mid y\right)=\frac{p\left(\mathscr{M}_{i}\right) p\left(y \mid \mathcal{M}_{i}\right)}{\sum_{j} p\left(\mathcal{M}_{j}\right) p\left(y \mid \mathcal{M}_{j}\right)} \quad\left(i=1, \ldots, 2^{k_{2}}\right),
$$


and if we take $p\left(\mathscr{M}_{i}\right)=2^{-k_{2}}$, which is the common assumption, then $p\left(\mathscr{M}_{i}\right)$ does not depend on $i$, and we have simply $\lambda_{i} \propto p\left(y \mid \mathcal{M}_{i}\right)$, the marginal likelihood of $y$ in model $\mathscr{M}_{i}$. If we adopt Zellner's $g$-prior (Zellner, 1986), then

where

$$
\lambda_{i} \propto\left(\frac{g_{i}}{1+g_{i}}\right)^{k_{2 i} / 2}\left(y^{\prime} M_{1} A_{i} M_{1} y\right)^{-\left(n-k_{1}\right) / 2}
$$

$$
A_{i}=\frac{g_{i}}{1+g_{i}} M_{1}+\frac{1}{1+g_{i}}\left(M_{1}-M_{1} X_{2 i}\left(X_{2 i}^{\prime} M_{1} X_{2 i}\right)^{-1} X_{2 i}^{\prime} M_{1}\right)
$$

and

$$
M_{1}=\left(I_{n}-X_{1}\left(X_{1}^{\prime} X_{1}\right)^{-1} X_{1}^{\prime}\right)
$$

We specify $g_{i}$ as

$$
g_{i}=\frac{1}{\max \left(n, k_{2}^{2}\right)}
$$

The $\lambda_{i}$ are the required weights to obtain the BMA estimates and precisions.

For example, the BMA estimator of $\beta_{1}$ is given by

$$
\mathrm{E}\left(\beta_{1} \mid y\right)=\sum_{i=1}^{k_{2}} \lambda_{i} \mathrm{E}\left(\beta_{1} \mid y, \mathcal{M}_{i}\right)
$$

There are several problems with BMA. First, all $2^{k_{2}}$ models have to be evaluated implying a huge computational effort; second, the priors are based on the normal distribution, leading to unbounded risk; and third, the treatment of 'ignorance' is ad hoc and unsatisfactory. These problems are avoided in an alternative model averaging procedure, called WALS.

\subsection{Weighted Average Least Squares (WALS)}

In the WALS algorithm, developed in Magnus et al. (2010, Section 3), we first 'orthogonalize' the columns of $X_{2}$ such that $P^{\prime} X_{2}^{\prime} M_{1} X_{2} P=\Lambda$, where $P$ is orthogonal and $\Lambda$ is diagonal. Then we define $X_{2}^{*}=X_{2} P \Lambda^{-1 / 2}$ and $\beta_{2}^{*}=\Lambda^{1 / 2} P^{\prime} \beta_{2}$, so that $X_{2}^{*} \beta_{2}^{*}=X_{2} \beta_{2}$. Our prior will be on $\beta_{1}$ and $\beta_{2}^{*}$ (rather than on $\beta_{2}$ ), and this gives us enormous computational advantage, because all models which include $x_{2 j}^{*}$ as a regressor will have the same estimator of $\beta_{2 j}^{*}$, irrespective which other $\beta_{2}^{*}$ 's are estimated.

The second ingredient is the 'equivalence theorem' (Magnus and Durbin, 1999; Danilov and Magnus, 2004), which tells us that the WALS estimator $b_{1}$ of $\beta_{1}$ will be 'good' (in the mean squared error sense) if and only if $W \hat{\beta}_{2}^{*}$ is a good estimator of $\beta_{2}^{*}$, where $\hat{\beta}_{2}^{*}$ denotes the least squares estimator of $\beta_{2}^{*}$ in the unrestricted model, and $W$ is a random diagonal matrix of order $k_{2} \times k_{2}$. The diagonal elements $w_{j}$ of $W$ will depend on the weights $\lambda_{i}$, but while there are $2^{k_{2}}$ $\lambda$ 's, there are only $k_{2} w$ 's. This is where the computational advantage comes from.

The third ingredient is the treatment of ignorance. Based on the fact that a $t$-value of one indicates that including an auxiliary regressor gives us the same mean squared error of the estimated focus parameter as excluding the auxiliary regressor, we define ignorance on an auxiliary parameter $\eta$ by the properties 
and we propose the Laplace distribution

$$
\operatorname{Pr}(\eta>0)=\operatorname{Pr}(\eta<0), \quad \operatorname{Pr}(|\eta|>1)=\operatorname{Pr}(|\eta|<1),
$$

with $c=\log 2$.

$$
\pi(\eta)=(c / 2) \exp (-c|\eta|)
$$

The WALS estimator is a Bayesian combination of frequentist estimators, and possesses major advantages over standard Bayesian model averaging (BMA) estimators: the WALS estimator has bounded risk, allows a coherent treatment of ignorance, and its computational effort is negligible. The sampling properties of the WALS estimator as compared to BMA estimators have been examined in Magnus et al. (2011), where Monte Carlo evidence shows that the WALS estimator performs better than standard BMA and pretest alternatives. Because of the light computational cost, extensions are possible in many directions. For example, Magnus et al. (2011) extend the WALS theory to allow for nonspherical disturbances.

In the current paper we consider a broader class of linear models than before, by allowing the regressors to include lagged dependent variables. The $y_{t}$ will then be correlated with the current and all previous disturbances, but uncorrelated with all future disturbances. Hence, the regressor $y_{t-1}$ will be uncorrelated with the current disturbance and all future disturbances, although it will be correlated with all previous disturbances. The standard ordinary least squares (OLS) assumptions do therefore not hold, and the finite-sample properties of the least squares estimators are not valid. However, as shown by Mann and Wald (1943), these properties will hold asymptotically.

We need to determine which variables are focus and which are auxiliary. The focus variables are those which we want in the model on theoretical or other grounds, irrespective of any diagnostics. The choice is not always easy and often subjective. It is guided by economictheoretical considerations and by previous empirical experience. But it is also guided by the purpose of the model: if our primary purpose is to study the effect of $x$ and $z$ on $y$, then it would seem ill-advised to remove $x$ or $z$ from the model; these are necessarily focus variables.

In our setting, we shall assume that the lagged dependent variables are always focus regressors. But the extracted principal components can be either focus or auxiliary. Thus we write

$$
y=X_{1} \beta_{1}+X_{2} \beta_{2}+\varepsilon
$$

where $X_{1}$ contains the lagged dependent variables and a subset (possible empty) of the principal components, and $X_{2}$ contains the remainder of the principal components. In this form we can apply BMA and WALS to this system.

\section{CHARACTERISTICS OF ARMENIA}

Armenia is a small country in the Southern Caucasus, slightly larger than Wales, slightly smaller than Belgium, and about 65\% the size of Moscow region. Most of its territory (80\%) consists of mountains. It is bordered by Georgia to the North and East, Azerbaijan to the West, and Turkey and Iran to the South. Armenia was the first nation to adopt Christianity as a state religion, in $301 \mathrm{AD}$. The population of Armenia, close to three million people, is homogeneous: about $98 \%$ is ethnic Armenian with some small minorities, mostly Yazidis $(1.3 \%)$ and Russians $(0.5 \%)$. 
Until 1991 Armenia was a republic of the former Soviet Union. During the Soviet period Armenia was transformed from an agricultural to an industrial society, and produced machine tools, electronic products, synthetic rubber, and textiles to trade with other Soviet republics in exchange for raw materials and energy. But the regional conflict with Azerbaijan over Nagorno-Karabakh and the break-up of the Soviet Union contributed to a severe economic decline in the early 1990s. As a result, GDP in 1992/93 was only about $40 \%$ of the level in 1989.

In 1994 the Armenian Government launched an ambitious IMF-sponsored economic program, which has resulted in positive growth since 1995. Today, Armenia's economy is stable with a high growth rate and low inflation. From 2000-2009 the economy grew at an annual average rate of $8.8 \%$, while the inflation rate was $3.0 \%$. The reason for this rapid growth lies mainly in the expanding construction and service sectors; according to Armenia's National Statistical Agency, the construction sector accounted for about 27\% of GDP in 2008. Cash remittances from migrant workers (of which $95 \%$ are employed in Russia) are another important factor.

Despite marked progress, Armenia still suffers from a large trade imbalance which is an impediment to economic growth. Armenia is largely dependent upon foreign aid and remittances from Armenian nationals working abroad. The total value of foreign debt is high: the ratio between GDP and foreign debt has reached $46 \%$. The unemployment rate is nearly $30 \%$, and a huge gap exists between actual and potential GDP.

\section{DATA DESCRIPTION AND PRELIMINARY ANALYSIS}

Our data consist of quarterly time series of 42 macroeconomic variables from 2000 (second quarter) to 2010 (fourth quarter), in total 43 observations for each variable. This set comprises information on national accounts data (9 variables) and consumer prices and exchange rate data (13 variables), listed in Table 5.1; and on financial and monetary policy indicators (13 variables) and international macroeconomic indicators (7 variables), listed in Table 5.2. All variables in Table 5.1 are in logarithmic form, in first differences. The variables in column 1 are all real. The variables in columns 1 and 2 are seasonally adjusted.

\begin{tabular}{lll}
\hline \hline National accounts & Price indices & Price indices and exchange rates \\
\hline GDP & Consumer price index & Wheat price index \\
Consumption & Food price index & Fuel price index \\
Investment & Nonfood price index & Imported food price index \\
Exports & Services price index & Imported nonfood price index \\
Imports & Home food price index & Administrative price index \\
Industrial output & & AMD/USD exchange rate \\
Agricultural output & & AMD/EURO exchange rate \\
Construction & & AMD/RR exchange rate \\
Services & \\
\hline \hline
\end{tabular}

Table 5.1 National accounts, consumer prices and exchange rates.

The variables in Table 5.2 are also in logarithmic form, in first differences, and the variables in columns 1 and 3 are seasonally adjusted. The international indicators in column 3 are taken from the International Financial Statistics (IFS) published by the IMF and are already seasonally adjusted.

The dependent variables are either 'growth', denoted $G$, defined as the quarterly growth rate of real GDP, and 'inflation', denoted $I N F$, defined as the quarterly growth rate of the consumer price index CPI. The dynamics of the observed quarterly real GDP data are 
presented in Figures 5.1 (real GDP) and 5.2 (growth), and the dynamics of the observed quarterly CPI data in Figures 5.3 (CPI) and 5.4 (inflation). We see from Figures 5.1-5.2 that the 2008 global economic crisis led to a sharp decrease in real GDP in the 4-th quarter of 2008. Real GDP declined by about $15 \%$ in 2009 compared to 2008, primarily because the remittance and private capital flow boom came to an end, leading to the collapse of the construction sector. Since 2010 the growth of real GDP is again positive. Figures 5.3-5.4 show that inflation has responded less dramatically during the global crisis; it remained low at about $3.5 \%$ in 2009 , due to weak domestic demand and low import prices.

\begin{tabular}{lll}
\hline \hline Financial policy indicators & Interest rates & International indicators \\
\hline Cash money & AMD deposits & USA real GDP \\
Money aggregate, M0 & USD deposits & EU real GDP \\
Money aggregate, M1 & AMD loans & USA consumer price index \\
Money aggregate, M2X & USD loans & EU consumer price index \\
Total deposits & Central Bank interbank & Gasoline price index \\
Loans to economy & & Petroleum price index \\
Loans to enterprizes & & Wheat price index \\
Loans to households & & \\
\hline \hline
\end{tabular}

Table 5.2 Financial, monetary and international indicators.

Figure 5.1 Seasonally adjusted real GDP, 2000/Q1-2010/Q4 (billion Armenian drams)

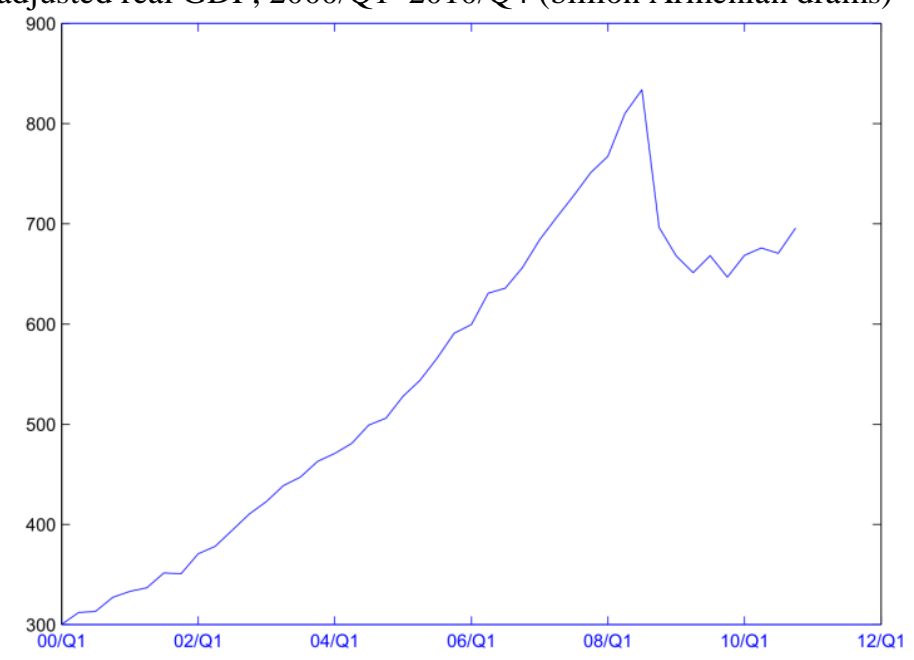

Figure 5.2 Quarterly growth rate of real GDP, 2000/Q2-2010/Q4

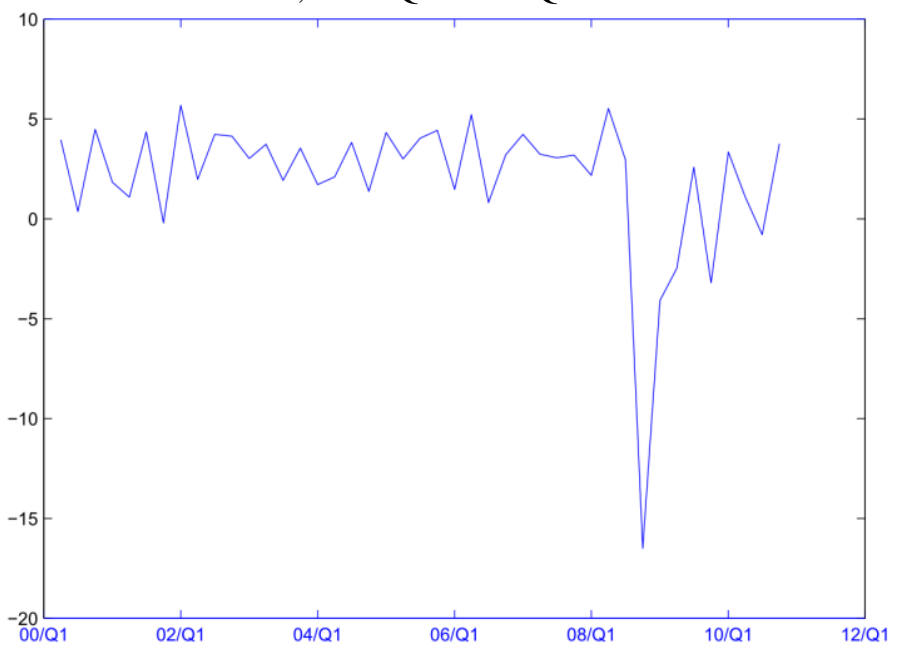


Figure 5.3 Seasonally adjusted CPI, 2000/Q1-2010/Q4 (2000/Q1 = 100)

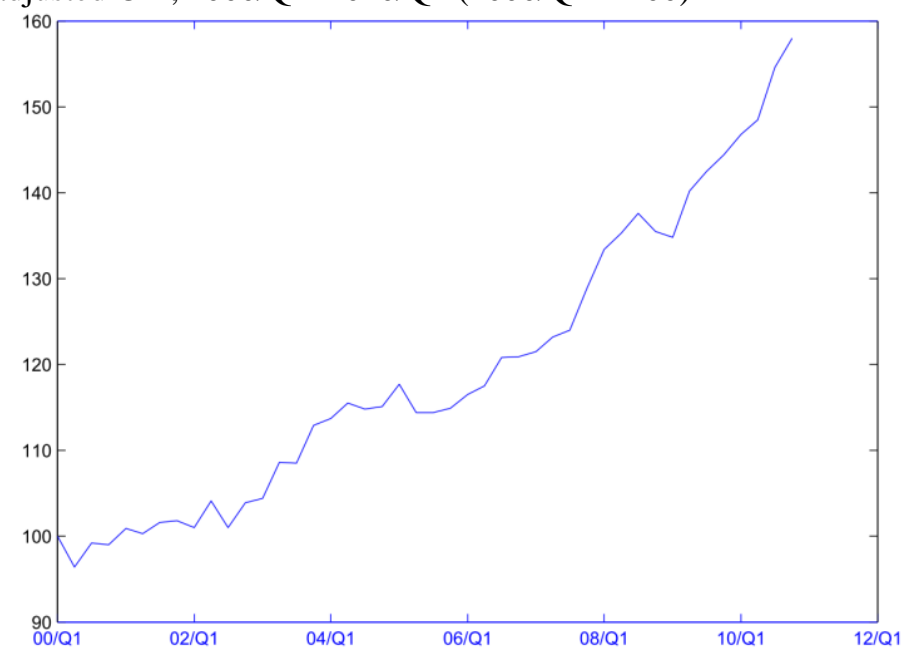

Figure 5.4 Inflation (quarterly growth rate of CPI), 2000/Q2-2010/Q4

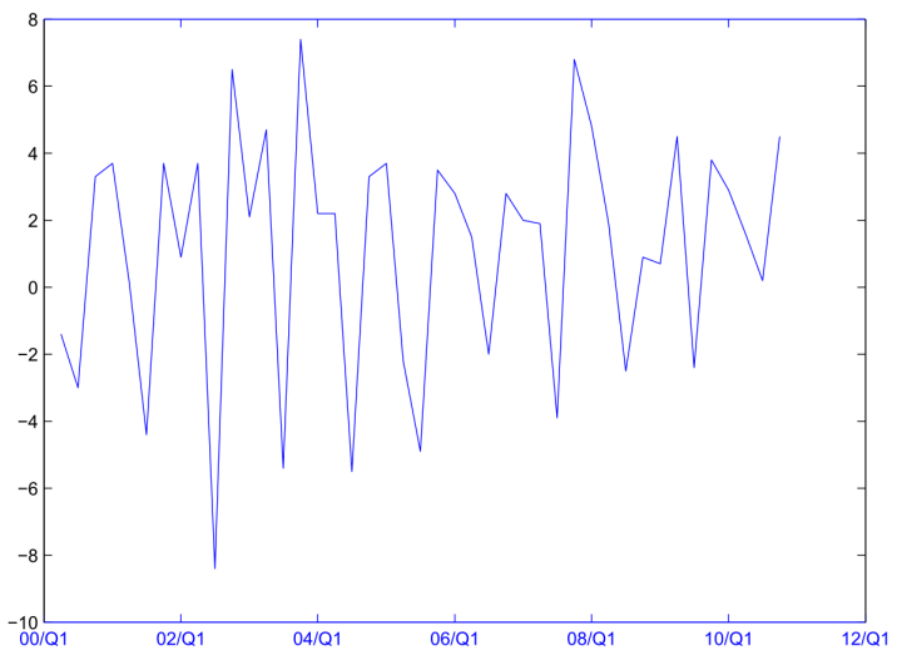

\begin{tabular}{lccccc}
\hline \hline $\begin{array}{l}\text { Principal } \\
\text { components }\end{array}$ & $\begin{array}{c}\text { Rotated } \\
\text { eigenvalue }\end{array}$ & $\begin{array}{c}\text { \% of total } \\
\text { variance }\end{array}$ & $\begin{array}{c}\text { Cumulative } \\
\%\end{array}$ & $\begin{array}{c}\text { Correlation } \\
\text { with growth }\end{array}$ & $\begin{array}{c}\text { Correlation } \\
\text { with inflation }\end{array}$ \\
\hline Int_rate & 5.11 & 12.78 & 12.78 & 0.04 & -0.21 \\
Ex_rate & 5.00 & 12.51 & 25.29 & -0.03 & 0.28 \\
Invest & 3.90 & 9.74 & 35.03 & 0.65 & 0.07 \\
Mon_agg & 3.60 & 9.00 & 44.03 & 0.43 & 0.01 \\
Credit & 3.19 & 7.98 & 52.01 & 0.02 & 0.10 \\
Pr_index & 2.62 & 6.54 & 58.55 & 0.23 & 0.62 \\
ImpExp & 2.58 & 6.46 & 65.01 & 0.22 & -0.03 \\
Nat_acc & 2.37 & 5.93 & 70.93 & 0.31 & -0.27 \\
Gstar & 2.01 & 5.01 & 75.95 & 0.29 & -0.12 \\
Hfood_pr & 1.69 & 4.23 & 80.18 & 0.09 & 0.47 \\
\hline \hline
\end{tabular}

Table 5.3 Characteristics of the extracted principal components.

In this paper we estimate and forecast factor-based dynamic models using principal components. These principal components are based on the underlying data set of 40 variables (excluding dependent variables, that is real GDP growth and inflation). The extracted principal components have been given names, based on the correlation coefficients between the extracted principal components and the underlying time series. Some important characteristics of the extracted principal components are presented in the Table 5.3. The first 
principal component is Int_rate and its contribution to the total variance of the underlying variables is $12.78 \%$. The second principal component is Ex_rate with a contribution of $12.51 \%$, and the third is Invest with a contribution of $9.74 \%$. The ten most important principal components (those with a rotated eigenvalue larger than 1) explain more than $80 \%$ of the variance of the underlying variables, which we consider to be sufficient.

\begin{tabular}{lcclcc}
\hline \hline & Growth $G$ & & & Inflation INF & \\
\hline Regressor & Model 1.1 & Model 1.2 & Regressor & Model 2.1 & Model 2.2 \\
\hline Intercept & focus & focus & Intercept & focus & focus \\
$G_{t-j}$ & focus & focus & INF $_{t-j}$ & focus & focus \\
Invest $_{t-j}$ & auxiliary & focus & Ex_rate & auxiliary & focus \\
ImpExp $_{t-j}$ & auxiliary & focus & Pr_index $_{t-j}$ & auxiliary & focus \\
Nat_acc & auxiliary & focus & Hfood_pr $r_{t-j}$ & auxiliary & focus \\
Mon_agg $_{t-j}$ & auxiliary & auxiliary & Int_rate $_{t-j}$ & auxiliary & auxiliary \\
Pr_index $_{t-j}$ & auxiliary & auxiliary & Credit $_{t-j}$ & auxiliary & auxiliary \\
Gstar $_{t-j}$ & auxiliary & auxiliary & Nat_acc $_{t-j}$ & auxiliary & auxiliary \\
& & & Gstar $_{t-j}$ & auxiliary & auxiliary \\
\hline \hline
\end{tabular}

Table 5.4 Focus and auxiliary variables $(j=1, \ldots, 4)$.

Each of the extracted principal components could be used for estimation in our factor-based dynamic models. However, we use our knowledge of economic theory and Armenian practice to include only those principal components which contain important information about real GDP growth and inflation. Regarding real GDP growth, the highest correlations are obtained by Invest, Mon_agg, Pr_index, ImpExp, Nat_acc and Gstar. Regarding inflation, the highest correlations are obtained by Int_rate, Ex_rate, Credit, Pr_index, Nat_acc, Gstar and Hfood_pr.

These choices then lead to the four models in Table 5.4. Model 1 refers to GDP growth and Model 2 to inflation. Each model has two variants. In variant 1 (Models 1.1 and 2.1) we take as our focus variables only the lagged values of the dependent variable (and the intercept), while all other variables are auxiliary, that is, we are uncertain whether they should be in the model or not. This is the same type of specification as in Koop and Potter (2004). In variant 2 (Models 1.2 and 2.2) we have more focus variables. Here we argue that some of the extracted principal components must always be in the model so that they should be treated as focus variables. For Model 1.2 this applies to Invest, ImpExp, and Nat_acc, because the level of real GDP growth depends directly on the level of these components. For Model 2.2 it applies to Ex_rate, Pr_index and Hfood_pr, because these principal components are known to have a direct impact on the rate of inflation. Having thus specified the four models, we now turn to their estimation and forecasting using the WALS and BMA algorithms.

\section{ESTIMATION RESULTS}

We have two models, one for GDP growth and one for inflation. Each model has two variants, one with only the intercept and the lagged dependent variable as focus regressors, the other with additional focus regressors. For each of the four cases we consider one lag, two lags, three lags, or four lags. We do not use more than four lags, because, in practice, factorbased dynamic models (DFM) are mainly used for short-term forecasting, while for long-term forecasts practitioners typically use dynamic stochastic general equilibrium (DSGE) models. This is also true at the Central bank of Armenia: for short-term forecasts (up to four quarters) DFM and Bayesian VAR models are used, while DSGE models are used for long-term forecasts (two or more years). Since we work with quarterly data, four lags means one year, so that the lagged period (four quarters) equals the maximum predicted period. Of course, 
there is also considerable local experience with short-term forecasting, indicating that four lags provide a reasonable lag structure.

\begin{tabular}{|c|c|c|c|c|}
\hline & One lag & Two lags & Three lags & Four lags \\
\hline \multicolumn{5}{|c|}{ Focus regressors } \\
\hline Intercept & $0.43(0.52)$ & $1.05(0.78)$ & $2.51(1.43)$ & $1.02(1.90)$ \\
\hline$G_{t-1}$ & $0.77(0.24)$ & $0.97(0.31)$ & $0.92(0.45)$ & $0.78(0.57)$ \\
\hline$G_{t-2}$ & - & $-0.52(0.25)$ & $-1.11(0.41)$ & $-1.05(0.61)$ \\
\hline$G_{t-3}$ & - & - & $-0.13(0.29)$ & $0.51(0.72)$ \\
\hline$G_{t-4}$ & - & - & - & $0.20(0.48)$ \\
\hline \multicolumn{5}{|c|}{ Auxiliary regressors } \\
\hline Invest $_{t-1}$ & $-0.25(0.41)$ & $-0.49(0.47)$ & $-0.49(0.61)$ & $-0.35(0.73)$ \\
\hline $\operatorname{ImpExp}_{t-1}$ & $-0.14(0.25)$ & $-0.08(0.23)$ & $-0.01(0.26)$ & $0.12(0.37)$ \\
\hline$N a t_{-} a c c_{t-1}$ & $0.37(0.27)$ & $0.19(0.29)$ & $0.37(0.36)$ & $0.67(0.62)$ \\
\hline$M o \bar{n} \_a g g_{t-1}$ & $0.14(0.31)$ & $0.29(0.32)$ & $0.19(0.39)$ & $0.48(0.54)$ \\
\hline$P r_{-}$index $x_{t-1}$ & $0.10(0.23)$ & $0.17(0.29)$ & $0.08(0.36)$ & $0.19(0.37)$ \\
\hline Gstar $_{t-1}$ & $-0.22(0.27)$ & $0.03(0.32)$ & $-0.29(0.38)$ & $0.00(0.63)$ \\
\hline Invest $_{t-2}$ & - & $0.18(0.45)$ & $0.99(0.69)$ & $0.43(0.69)$ \\
\hline $\operatorname{ImpExp}_{t-2}$ & - & $0.24(0.23)$ & $0.35(0.26)$ & $0.26(0.44)$ \\
\hline Nat_acc $t_{t-2}$ & - & $0.68(0.28)$ & $0.92(0.34)$ & $0.79(0.52)$ \\
\hline$M o n \_a g g_{t-2}$ & - & $0.26(0.31)$ & $0.72(0.42)$ & $0.87(0.88)$ \\
\hline Pr_index $t_{t-2}$ & - & $-0.05(0.28)$ & $0.71(0.39)$ & $0.27(0.38)$ \\
\hline Gstar $_{t-2}$ & - & $-0.01(0.26)$ & $0.80(0.40)$ & $0.89(0.59)$ \\
\hline Invest $_{t-3}$ & - & - & $0.57(0.46)$ & $-0.79(1.36)$ \\
\hline $\operatorname{ImpExp}_{t-3}$ & - & - & $0.41(0.24)$ & $0.29(0.38)$ \\
\hline Nat_acc $t-3$ & - & - & $0.47(0.34)$ & $0.09(0.52)$ \\
\hline$M o n \_a g g_{t-3}$ & - & - & $0.65(0.38)$ & $0.35(0.59)$ \\
\hline$P r_{-}$index $x_{t-3}$ & - & - & $-0.22(0.29)$ & $-0.61(0.56)$ \\
\hline Gstar $_{t-3}$ & - & - & $-0.22(0.29)$ & $-0.76(0.91)$ \\
\hline Invest $_{t-4}$ & - & - & - & $-0.75(0.78)$ \\
\hline $\operatorname{ImpExp}_{t-4}$ & - & - & - & $-0.07(0.26)$ \\
\hline Nat_acc $c_{t-4}$ & - & - & - & $0.11(0.61)$ \\
\hline$M o n \_a g g_{t-4}$ & - & - & - & $-0.67(0.42)$ \\
\hline$P r_{-}$index $x_{t-4}$ & - & - & - & $-0.14(0.63)$ \\
\hline Gstar $_{t-4}$ & - & - & - & $-0.11(0.51)$ \\
\hline
\end{tabular}

Table 6.5 WALS estimates for Model 1 (Growth), Version 1.

In addition, we have two different model averaging algorithms: WALS and BMA. All WALS and BMA results are obtained using MATLAB codes, which are freely available from www.janmagnus.nl/items/BMA.pdf. The WALS estimates for the GDP growth equation are presented in Tables 6.5 and 6.6.

In Table 6.5 the focus variables are the intercept and lagged values of real GDP growth, while in Table 6.6 we add lagged values of Invest, ImpExp and Nat_acc to the focus variables. The first lag $G_{t-1}$ of real GDP growth is positively correlated with current GDP growth $G_{t}$ and the parameter appears to be close to one in both models, and in each of the four lag structures, showing a certain amount of robustness. Current GDP growth is negatively correlated with lagged values of Invest, and positively correlated with Nat_acc. This is to be expected, since one of the main ingredients of Nat_acc is final consumption, which in turn is one of the basic components of GDP. Thus, final consumption should be positively correlated with GDP. Also, current consumption is positively correlated with consumption in the previous period, and hence consumption of the previous period and GDP of the current period should be positively correlated. The Mon_agg component is also positively correlated with current real GDP growth, which tells us that monetary aggregates can be considered as potential leading indicators for changes in the dynamics of real GDP. 


\begin{tabular}{|c|c|c|c|c|}
\hline & One lag & Two lags & Three lags & Four lags \\
\hline \multicolumn{5}{|c|}{ Focus regressors } \\
\hline Intercept & $0.37(0.54)$ & $0.98(0.83)$ & $2.56(1.40)$ & $1.18(1.94)$ \\
\hline$G_{t-1}$ & $0.80(0.25)$ & $1.08(0.33)$ & $1.08(0.45)$ & $0.85(0.58)$ \\
\hline Invest $_{t-1}$ & $-0.40(0.46)$ & $-0.85(0.52)$ & $-0.89(0.61)$ & $-0.62(0.76)$ \\
\hline $\operatorname{ImpExp} \operatorname{Ex}_{t-1}$ & $-0.21(0.28)$ & $-0.12(0.25)$ & $-0.02(0.27)$ & $0.06(0.41)$ \\
\hline Nat_acc $c_{t-1}$ & $0.54(0.30)$ & $0.18(0.32)$ & $0.28(0.37)$ & $0.58(0.64)$ \\
\hline$G_{t-2}$ & - & $-0.60(0.26)$ & $-1.29(0.43)$ & $-1.15(0.64)$ \\
\hline Invest $_{t-2}$ & 一 & $0.20(0.48)$ & $1.17(0.71)$ & $0.45(0.74)$ \\
\hline $\operatorname{ImpExp}_{t-2}$ & 一 & $0.29(0.26)$ & $0.42(0.28)$ & $0.28(0.46)$ \\
\hline Nat_acc $c_{t-2}$ & - & $0.94(0.31)$ & $1.18(0.36)$ & $1.01(0.54)$ \\
\hline$G_{t-3}$ & 一 & - & $-0.14(0.30)$ & $0.51(0.74)$ \\
\hline Invest $_{t-3}$ & - & - & $0.74(0.48)$ & $-0.71(1.38)$ \\
\hline $\operatorname{Imp} \operatorname{Exp}_{t-3}$ & - & - & $0.49(0.26)$ & $0.31(0.40)$ \\
\hline Nat_acc $c_{t-3}$ & - & - & $0.55(0.37)$ & $0.14(0.56)$ \\
\hline$G_{t-4}$ & - & - & - & $0.15(0.52)$ \\
\hline Invest $_{\mathrm{t}-4}$ & 一 & - & 一 & $-0.57(0.83)$ \\
\hline $\operatorname{Imp} \operatorname{Exp}_{\mathrm{t}-4}$ & - & - & 一 & $0.00(0.29)$ \\
\hline$N a t \_a c c_{t-4}$ & - & - & - & $0.18(0.65)$ \\
\hline \multicolumn{5}{|c|}{ Auxiliary regressors } \\
\hline Mon_agg $g_{t-1}$ & $0.13(0.31)$ & $0.26(0.31)$ & $0.11(0.38)$ & $0.48(0.53)$ \\
\hline Pr_index $t_{t-1}$ & $0.08(0.23)$ & $0.16(0.27)$ & $0.06(0.34)$ & $0.19(0.37)$ \\
\hline Gstar $_{t-1}$ & $-0.20(0.26)$ & $0.04(0.31)$ & $-0.28(0.38)$ & $-0.06(0.62)$ \\
\hline Mon $\operatorname{agg}_{t-2}$ & - & $0.25(0.30)$ & $0.72(0.41)$ & $0.92(0.89)$ \\
\hline Pr_index $t_{t-2}$ & - & $-0.03(0.25)$ & $0.73(0.39)$ & $0.28(0.39)$ \\
\hline Gstar $_{t-2}$ & - & $0.01(0.25)$ & $0.80(0.41)$ & $0.93(0.59)$ \\
\hline$M o n \_a g g_{t-3}$ & - & - & $0.63(0.38)$ & $0.36(0.58)$ \\
\hline Pr_index $t_{t-3}$ & - & - & $-0.18(0.28)$ & $-0.55(0.56)$ \\
\hline Gstar $_{t-3}$ & - & - & $-0.20(0.28)$ & $-0.79(0.91)$ \\
\hline Mon_agg $g_{t-4}$ & - & - & - & $-0.67(0.44)$ \\
\hline Pr_index $t_{t-4}$ & - & - & - & $-0.14(0.65)$ \\
\hline Gstar $_{t-4}$ & - & - & - & $-0.24(0.54)$ \\
\hline
\end{tabular}

Table 6.6 WALS estimates for Model 1 (Growth), Version 2.

Concerning Invest we see that the first lag is negatively correlated with current GDP growth, but that higher lags are positively correlated. Apparently, investments have a short-term (one quarter) negative impact, but a medium-term (2-4 quarters) positive impact on economic activity (and therefore on the growth level). Many of the auxiliary parameters are not statistically significant.

In Tables 6.7 and 6.8 we report the corresponding results for inflation. Lagged values of inflation are positively correlated with current inflation, but comparing with the growth estimates we find that inflation in Armenia is less backward-looking than growth. The first lags of Pr_index and Ex_rate are positively correlated with current inflation, which is again reasonable. The positive correlation between Pr_index and inflation tells us that price fluctuations in Armenia are autocorrelated. It appears that Ex_rate dynamics are positively correlated with inflation, due to the fact that Armenia is a small open economy with an imports-to-GDP ratio of about $40 \%$. The home price index therefore depends strongly on the international price index level.

Finally, let us compare Table 6.5 with Table 6.6 and Table 6.7 with Table 6.8. The difference between the tables is that there are fewer focus variables in Table 6.5 (version 1) than in Table 6.6 (version 2), and similarly, fewer focus variables in Table 6.7 than in Table 6.8. A comparison between the results tells us that the estimates are generally of the same sign and 
size. Concerning the standard errors two remarkable findings emerge. First, the standard error of a parameter is generally higher when the parameter is a focus parameter than when it is treated as an auxiliary parameter. For example, the parameter corresponding to Invest $_{t-1}$ in the one-lag model has standard error 0.41 in version 1 , and 0.46 in version 2 . Second, when there are more focus variables, the standard errors of the parameters corresponding to auxiliary variables (such as Gstar $_{t-1}$ ) become (slightly) smaller. These findings appear to be quite general and robust. The second result is quite intuitive: more things are fixed (more focus variables) and hence the standard errors become smaller. But the first result is puzzling and potentially important: if we treat a variable as auxiliary while it should be treated as focus, then we obtain standard errors that are misleadingly small, leading to too much confidence in our results.

\begin{tabular}{|c|c|c|c|c|}
\hline & One lag & Two lags & Three lags & Four lags \\
\hline \multicolumn{5}{|c|}{ Focus regressors } \\
\hline Intercept & $0.87(0.33)$ & $0.16(0.59)$ & $0.32(0.88)$ & $-0.54(1.88)$ \\
\hline$I N F_{t-1}$ & $0.27(0.27)$ & $0.66(0.37)$ & $0.35(0.69)$ & $0.69(1.41)$ \\
\hline$I N F_{t-2}$ & - & $0.20(0.30)$ & $0.38(0.58)$ & $0.72(1.16)$ \\
\hline$I N F_{t-3}$ & - & - & $-0.01(0.44)$ & $-0.56(0.82)$ \\
\hline$I N F_{t-4}$ & - & - & - & $0.62(0.74)$ \\
\hline \multicolumn{5}{|c|}{ Auxiliary regressors } \\
\hline$E x \_r a t e_{t-1}$ & $0.13(0.13)$ & $-0.02(0.18)$ & $0.07(0.26)$ & $-0.07(0.42)$ \\
\hline$P r_{-}$index $x_{t-1}$ & $0.31(0.21)$ & $0.14(0.25)$ & $0.33(0.43)$ & $0.27(0.81)$ \\
\hline Hfood_pr $r_{t-1}$ & $0.01(0.19)$ & $-0.29(0.26)$ & $-0.14(0.40)$ & $-0.47(0.83)$ \\
\hline Int_rate $_{t-1}$ & $-0.06(0.12)$ & $0.28(0.45)$ & $0.20(0.70)$ & $0.60(0.93)$ \\
\hline Credit $_{t-1}$ & $0.09(0.11)$ & $-0.24(0.22)$ & $-0.19(0.38)$ & $-0.02(0.53)$ \\
\hline$N a t_{-} a c c_{t-1}$ & $-0.03(0.13)$ & $0.11(0.19)$ & $0.07(0.27)$ & $0.12(0.37)$ \\
\hline Gstar $_{t-1}$ & $-0.17(0.12)$ & $0.03(0.19)$ & $0.04(0.34)$ & $0.21(0.55)$ \\
\hline Ex_rate $_{t-2}$ & - & $-0.01(0.16)$ & $-0.06(0.30)$ & $0.08(0.50)$ \\
\hline$P r_{-}$index $t_{t-2}$ & - & $-0.24(0.26)$ & $-0.20(0.34)$ & $-0.52(0.62)$ \\
\hline Hfood_pr $r_{t-2}$ & - & $-0.15(0.22)$ & $-0.26(0.44)$ & $-0.57(0.83)$ \\
\hline Int_rate $_{t-2}$ & - & $-0.31(0.43)$ & $0.09(0.76)$ & $-0.59(1.35)$ \\
\hline Credit $_{t-2}$ & - & $0.28(0.20)$ & $0.00(0.46)$ & $0.11(0.93)$ \\
\hline$N a t_{-} a c c_{t-2}$ & - & $0.11(0.15)$ & $0.22(0.27)$ & $0.44(0.49)$ \\
\hline Gstar $_{t-2}$ & - & $-0.10(0.15)$ & $0.07(0.29)$ & $0.17(0.64)$ \\
\hline$E_{-}$rate $_{t-3}$ & - & - & $0.11(0.28)$ & $0.19(0.48)$ \\
\hline$P r_{-}$index $x_{t-3}$ & - & - & $-0.15(0.39)$ & $0.02(0.52)$ \\
\hline Hfood_pr $r_{t-3}$ & - & - & $-0.14(0.31)$ & $0.28(0.58)$ \\
\hline Int_rate $_{t-3}$ & - & - & $-0.39(0.69)$ & $-0.72(0.99)$ \\
\hline Credit $_{t-3}$ & - & - & $0.20(0.31)$ & $0.14(0.73)$ \\
\hline$N a t_{-} a c c_{t-3}$ & - & - & $-0.07(0.22)$ & $-0.09(0.39)$ \\
\hline Gstar $_{t-3}$ & - & - & $-0.13(0.20)$ & $-0.19(0.48)$ \\
\hline Ex_rate $_{t-4}$ & - & - & - & $-0.03(0.42)$ \\
\hline$P r_{-}$index $x_{t-4}$ & - & - & - & $-0.24(0.57)$ \\
\hline Hfood_pr $r_{t-4}$ & - & - & - & $-0.32(0.42)$ \\
\hline Int_rate $_{t-4}$ & - & - & - & $0.89(1.20)$ \\
\hline Credit $_{t-4}$ & - & - & - & $0.05(0.47)$ \\
\hline$N a t_{-} a c c_{t-4}$ & - & - & - & $0.04(0.30)$ \\
\hline Gstar $_{t-4}$ & - & - & - & $-0.15(0.33)$ \\
\hline
\end{tabular}

Table 6.7 WALS estimates for Model 2 (Inflation), Version 1.

\section{AN ESTIMATION SIMULATION EXPERIMENT}

While the previous results are of practical and theoretical interest, a proper comparison between WALS and BMA can only be done through a simulation experiment, where we know the data-generating process (DGP) and can therefore relate the estimates to the truth. The DGP that we have chosen follows closely the models estimated in the previous section. 
We conduct the simulation experiments for one, two, and three lags, so that we gain insight on the performance of the WALS and BMA algorithms for various lag lengths. In Tables 7.9 and 7.10 we present the parameter values in the data-generating processes for the growth and inflation models, respectively.

\begin{tabular}{|c|c|c|c|c|}
\hline & One lag & Two lags & Three lags & Four lags \\
\hline \multicolumn{5}{|c|}{ Focus regressors } \\
\hline Intercept & $0.93(0.34)$ & $0.06(0.62)$ & $0.09(0.91)$ & $-0.73(1.86)$ \\
\hline$I N F_{t-1}$ & $0.22(0.28)$ & $0.66(0.40)$ & $0.29(0.72)$ & $0.48(1.46)$ \\
\hline$E x \_r a t e_{t-1}$ & $0.17(0.15)$ & $0.00(0.21)$ & $0.10(0.30)$ & $-0.05(0.45)$ \\
\hline$P r \_$index $x_{t-1}$ & $0.42(0.23)$ & $0.24(0.29)$ & $0.43(0.47)$ & $0.46(0.85)$ \\
\hline$H f o o d \_p r_{t-1}$ & $-0.04(0.21)$ & $-0.38(0.29)$ & $-0.21(0.43)$ & $-0.46(0.86)$ \\
\hline$I N F_{t-2}$ & - & $0.28(0.31)$ & $0.48(0.62)$ & $0.88(1.20)$ \\
\hline$E x \_$rate $_{t-2}$ & - & $-0.03(0.19)$ & $-0.14(0.33)$ & $0.06(0.53)$ \\
\hline$P r \_$index $t_{t-2}$ & 一 & $-0.35(0.29)$ & $-0.25(0.38)$ & $-0.57(0.66)$ \\
\hline Hfood_pr $r_{t-2}$ & - & $-0.20(0.26)$ & $-0.28(0.48)$ & $-0.68(0.86)$ \\
\hline$I N F_{t-3}$ & 一 & - & $0.14(0.47)$ & $-0.50(0.86)$ \\
\hline$E x \_r a t e_{t-3}$ & 一 & - & $0.13(0.30)$ & $0.19(0.51)$ \\
\hline$P r \_$index $t_{t-3}$ & 一 & - & $-0.31(0.43)$ & $-0.04(0.57)$ \\
\hline$H f o o d \_p r_{t-3}$ & - & - & $-0.29(0.35)$ & $0.21(0.62)$ \\
\hline$I N F_{t-4}$ & 一 & - & - & $0.77(0.76)$ \\
\hline$E x \_$rate $_{t-4}$ & 一 & 一 & 一 & $0.01(0.44)$ \\
\hline$P r_{-}$index $t_{t-4}$ & - & 一 & 一 & $-0.41(0.61)$ \\
\hline Hfood_pr $r_{t-4}$ & - & - & 一 & $-0.48(0.47)$ \\
\hline \multicolumn{5}{|c|}{ Auxiliary regressors } \\
\hline Int_rate $_{t-1}$ & $-0.06(0.12)$ & $0.28(0.45)$ & $0.20(0.70)$ & $0.59(0.92)$ \\
\hline Credit $_{t-1}$ & $0.08(0.11)$ & $-0.24(0.22)$ & $-0.19(0.38)$ & $-0.01(0.53)$ \\
\hline$N a t \_a c c_{t-1}$ & $-0.04(0.13)$ & $0.11(0.19)$ & $0.07(0.27)$ & $0.12(0.36)$ \\
\hline Gstar $_{t-1}$ & $-0.16(0.11)$ & $0.04(0.19)$ & $0.05(0.34)$ & $0.21(0.55)$ \\
\hline Int_rate $_{t-2}$ & - & $-0.30(0.43)$ & $0.10(0.75)$ & $-0.57(1.35)$ \\
\hline Credit $_{t-2}$ & - & $0.28(0.20)$ & $0.00(0.46)$ & $0.10(0.94)$ \\
\hline$N a t \_a c c_{t-2}$ & - & $0.11(0.15)$ & $0.21(0.27)$ & $0.44(0.49)$ \\
\hline Gstar $_{t-2}$ & - & $-0.09(0.15)$ & $0.07(0.29)$ & $0.17(0.64)$ \\
\hline Int_rate $_{t-3}$ & - & - & $-0.39(0.69)$ & $-0.74(0.99)$ \\
\hline Credit $_{t-3}$ & - & - & $0.20(0.31)$ & $0.14(0.75)$ \\
\hline$N a t \_a c c_{t-3}$ & - & - & $-0.06(0.22)$ & $-0.10(0.39)$ \\
\hline Gstar $_{t-3}$ & - & - & $-0.13(0.20)$ & $-0.19(0.49)$ \\
\hline Int_rate $_{t-4}$ & - & - & - & $0.89(1.20)$ \\
\hline Credit $_{t-4}$ & - & - & - & $0.06(0.47)$ \\
\hline$N a t \_a c c_{t-4}$ & - & - & - & $0.03(0.30)$ \\
\hline Gstar $_{t-4}$ & - & - & - & $-0.15(0.33)$ \\
\hline
\end{tabular}

Table 6.8 WALS estimates for Model 2 (Inflation), Version 2.

We randomly draw the $\left\{u_{t}\right\}$ from a standard-normal distribution. Then, given the datagenerating process and the values of the regressors, we generate the time series for real GDP growth or inflation, the dependent variables. Now that we have all the data, we estimate the parameters using the models and the estimation algorithms of Section 6. This gives us parameter estimates. Next we draw new errors $\left\{u_{t}\right\}$, obtain new values for the dependent variable, and hence new parameter estimates. We repeat this 1000 times, and compute the simulation root mean squared errors (RMSE):

$$
\begin{aligned}
\operatorname{RMSE}_{k}^{\text {wals }} & =\sqrt{\frac{1}{1000} \sum_{l=1}^{1000}\left(\beta_{k}^{\text {wals }}-\beta_{k}^{\text {true }}\right)^{2}}, \\
\operatorname{RMSE}_{k}^{\text {bma }} & =\sqrt{\frac{1}{1000} \sum_{l=1}^{1000}\left(\beta_{k}^{\text {bma }}-\beta_{k}^{\text {true }}\right)^{2}},
\end{aligned}
$$


where $\beta_{k}^{\text {true }}$ denotes the true value of $\beta_{k} ; \beta_{k}^{\text {walsl }}$ and $\beta_{k}^{\text {bmal }}$ are the corresponding WALS and BMA estimates, respectively, for the $l$-th iteration.

\begin{tabular}{lccc}
\hline \hline & One lag & Two lags & Three lags \\
\hline Intercept & 0.50 & 1.20 & 3.00 \\
$G_{t-1}$ & 0.75 & 0.95 & 0.80 \\
Invest $_{t-1}$ & -0.30 & -0.70 & -0.40 \\
ImpExp $_{t-1}$ & -0.15 & 0.00 & 0.10 \\
Nat_acc $_{t-1}$ & 0.60 & 0.15 & 0.55 \\
Mon_agg $_{t-1}$ & 0.30 & 0.40 & 0.40 \\
Pr_index $_{t-1}$ & 0.20 & 0.35 & 0.30 \\
Gstar $_{t-1}$ & -0.35 & 0.10 & -0.30 \\
G $_{t-2}$ & - & -0.60 & -1.30 \\
Invest $_{t-2}$ & - & 0.30 & 1.30 \\
ImpExp $_{t-2}$ & - & 0.30 & 0.40 \\
Nat_acc $_{t-2}$ & - & 0.95 & 1.15 \\
Mon_agg $_{t-2}$ & - & 0.40 & 0.70 \\
Pr_index $_{t-2}$ & - & -0.25 & 0.90 \\
Gstar $_{t-2}$ & - & 0.05 & 0.90 \\
G $_{t-3}$ & - & - & -0.10 \\
Invest $_{t-3}$ & - & - & 0.75 \\
ImpEEx $_{\mathrm{t}-3}$ & - & - & 0.45 \\
Nat_acc $_{t-3}$ & - & - & 0.60 \\
Mon_agg $_{t-3}$ & - & - & 0.90 \\
Pr_index $_{t-3}$ & - & - & -0.30 \\
Gstar $_{t-3}$ & - & - & -0.30 \\
\hline F $^{2}$ & 2.25 & 2.25 & 2.25 \\
\hline \hline
\end{tabular}

Table 7.9 Data-generation process for Model 1 (Growth), Version 2.

\begin{tabular}{lccc}
\hline \hline & One lag & Two lags & Three lags \\
\hline Intercept & 1.00 & 0.10 & -2.00 \\
INF $_{t-1}$ & 0.10 & 0.80 & 1.40 \\
Ex_rate $_{t-1}$ & 0.20 & 0.60 & -0.10 \\
Pr_index $_{t-1}$ & 0.55 & -0.15 & -0.15 \\
Hfood_pr $_{t-1}$ & 0.10 & -0.15 & -0.85 \\
Int_rate $_{t-1}$ & -0.20 & 0.00 & 0.50 \\
Credit $_{t-1}$ & 0.10 & -0.55 & -0.50 \\
Nat_acc $_{t-1}$ & -0.10 & -0.70 & 0.70 \\
Gstar $_{t-1}$ & -0.30 & -0.40 & 0.40 \\
INF $_{t-2}$ & - & 0.50 & 1.00 \\
Ex_rate $_{t-2}$ & - & -0.50 & -0.15 \\
Pr_index $_{t-2}$ & - & -0.50 & -0.75 \\
Hfood_pr $_{t-2}$ & - & 0.40 & -0.50 \\
Int_rate $_{t-2}$ & - & 0.50 & 0.60 \\
Credit $_{t-2}$ & - & 0.40 & 0.60 \\
Nat_acc $_{t-2}$ & - & 0.40 & 0.80 \\
Gstar $_{t-2}$ & - & 0.40 & 0.40 \\
INF $_{t-3}$ & - & - & 0.30 \\
Ex_rate $_{t-3}$ & - & - & 0.25 \\
Pr_index $_{t-3}$ & - & - & -0.65 \\
Hfood_pr $_{t-3}$ & - & - & -0.20 \\
Int_rate $_{t-3}$ & - & - & -0.50 \\
Credit $_{t-3}$ & - & - & 0.60 \\
Nat_acc $_{t-3}$ & - & - & -0.50 \\
Gstar $_{t-3}$ & - & - & 0.50 \\
\hline O $^{2}$ & 1.44 & 1.44 & 1.44 \\
\hline \hline
\end{tabular}

Table 7.10 Data-generation process for Model 2 (Inflation), Version 2. 


\begin{tabular}{|c|c|c|c|c|c|c|}
\hline & WALS & BMA & WALS & BMA & WALS & BMA \\
\hline Intercept & 0.0373 & 0.0375 & 0.0293 & 0.0270 & 0.0330 & 0.0399 \\
\hline$G_{t-1}$ & 0.0192 & 0.0193 & 0.0292 & 0.0283 & 0.0247 & 0.0222 \\
\hline Invest $_{t-1}$ & 0.0340 & 0.0341 & 0.0366 & 0.0362 & 0.0212 & 0.0216 \\
\hline $\operatorname{Imp} \operatorname{Exp}_{t-1}$ & 0.0129 & 0.0130 & 0.0116 & 0.0118 & 0.0101 & 0.0099 \\
\hline Nat_acc $c_{t-1}$ & 0.0172 & 0.0173 & 0.0190 & 0.0199 & 0.0132 & 0.0122 \\
\hline Mon_agg & 0.0164 & 0.0206 & 0.0142 & 0.0151 & 0.0134 & 0.0180 \\
\hline Pr_index ${ }_{t-1}$ & 0.0099 & 0.0110 & 0.0100 & 0.0124 & 0.0104 & 0.0119 \\
\hline Gstar $_{t-1}$ & 0.0154 & 0.0126 & 0.0132 & 0.0064 & 0.0202 & 0.0148 \\
\hline$G_{t-2}$ & - & - & 0.0163 & 0.0170 & 0.0380 & 0.0395 \\
\hline Invest $_{t-2}$ & - & - & 0.0146 & 0.0141 & 0.0480 & 0.0516 \\
\hline $\operatorname{ImpExp}_{t-2}$ & - & - & 0.0092 & 0.0099 & 0.0113 & 0.0119 \\
\hline$N a t \_a c c_{t-2}$ & - & - & 0.0105 & 0.0109 & 0.0161 & 0.0171 \\
\hline Mon-agg & - & - & 0.0082 & 0.0098 & 0.0150 & 0.0194 \\
\hline Pr-index $t_{t-2}$ & - & - & 0.0097 & 0.0088 & 0.0259 & 0.0259 \\
\hline Gstar $_{t-2}$ & - & - & 0.0124 & 0.0065 & 0.0254 & 0.0288 \\
\hline$G_{t-3}$ & - & - & - & - & 0.0056 & 0.0053 \\
\hline Invest $_{t-3}$ & - & - & - & - & 0.0263 & 0.0244 \\
\hline $\operatorname{ImpExp}_{\mathrm{t}-3}$ & - & - & - & - & 0.0124 & 0.0134 \\
\hline$N a t \_a c c_{t-3}$ & - & - & - & - & 0.0138 & 0.0140 \\
\hline Mon_agg $g_{t-3}$ & - & - & - & - & 0.0161 & 0.0202 \\
\hline Pr_index ${ }_{t-3}$ & - & - & - & - & 0.0104 & 0.0087 \\
\hline Gstar $_{t-3}$ & - & - & - & - & 0.0109 & 0.0088 \\
\hline
\end{tabular}

Table 7.11 RMSE for estimation simulations, Model 1 (Growth), Version 2.

\begin{tabular}{|c|c|c|c|c|c|c|}
\hline & WALS & BMA & WALS & BMA & WALS & BMA \\
\hline Intercept & 0.0095 & 0.0089 & 0.0529 & 0.0538 & 0.0882 & 0.0910 \\
\hline$I N F_{t-1}$ & 0.0067 & 0.0062 & 0.0261 & 0.0257 & 0.0409 & 0.0416 \\
\hline$E_{1} \_$rate $_{t-1}$ & 0.0061 & 0.0061 & 0.0126 & 0.0124 & 0.0174 & 0.0180 \\
\hline Pr_index ${ }_{t-1}$ & 0.0065 & 0.0065 & 0.0161 & 0.0163 & 0.0269 & 0.0252 \\
\hline Hfood_pr $r_{t-1}$ & 0.0067 & 0.0067 & 0.0200 & 0.0216 & 0.0341 & 0.0354 \\
\hline Int_rate $_{t-1}$ & 0.0052 & 0.0057 & 0.0197 & 0.0184 & 0.0455 & 0.0253 \\
\hline Credit $_{\mathrm{t}-1}$ & 0.0047 & 0.0038 & 0.0138 & 0.0163 & 0.0210 & 0.0202 \\
\hline Nat_acc $c_{t-1}$ & 0.0046 & 0.0038 & 0.0117 & 0.0138 & 0.0198 & 0.0209 \\
\hline Gstar $_{t-1}$ & 0.0052 & 0.0070 & 0.0101 & 0.0127 & 0.0171 & 0.0123 \\
\hline$I N F_{t-2}$ & - & - & 0.0195 & 0.0204 & 0.0341 & 0.0351 \\
\hline$E_{x} \_r a t e_{t-2}$ & - & - & 0.0093 & 0.0073 & 0.0127 & 0.0107 \\
\hline$P r_{-}$index $_{t-2}$ & - & - & 0.0189 & 0.0187 & 0.0297 & 0.0318 \\
\hline Hfood_pr $r_{t-2}$ & - & - & 0.0127 & 0.0120 & 0.0210 & 0.0215 \\
\hline Int_rate $_{t-2}$ & - & - & 0.0169 & 0.0135 & 0.0318 & 0.0252 \\
\hline Credit $_{t-2}$ & - & - & 0.0115 & 0.0127 & 0.0164 & 0.0132 \\
\hline$N a t_{-} a c c_{t-2}$ & - & - & 0.0089 & 0.0092 & 0.0185 & 0.0224 \\
\hline Gstar $_{t-2}$ & - & - & 0.0064 & 0.0092 & 0.0120 & 0.0108 \\
\hline$I N F_{t-3}$ & - & - & - & - & 0.0111 & 0.0105 \\
\hline$E x \_r a t e_{t-3}$ & - & - & - & - & 0.0117 & 0.0084 \\
\hline$P r \_i n d e x_{t-3}$ & - & - & - & - & 0.0134 & 0.0108 \\
\hline Hfood_pr $r_{t-3}$ & - & - & - & - & 0.0115 & 0.0115 \\
\hline Int_rate $_{t-3}$ & - & - & - & - & 0.0289 & 0.0176 \\
\hline Credit $_{t-3}$ & - & - & - & - & 0.0161 & 0.0161 \\
\hline Nat_acc $c_{t-3}$ & - & - & - & - & 0.0084 & 0.0124 \\
\hline Gstar $_{t-3}$ & - & - & - & - & 0.0097 & 0.0106 \\
\hline
\end{tabular}

Table 7.12 RMSE for estimation simulations, Model 2 (Inflation), Version 2.

The results of the Monte-Carlo simulations are presented in Tables 7.11 (for growth) and 7.12 (for inflation). The main purpose of these simulations is to compare BMA and WALS. WALS has certain theoretical and computational advantages, but does it in fact perform better than BMA? The simulations suggest that this might be the case, although the difference is small. In the growth simulations, WALS achieves a lower RMSE than BMA for 88\% (one lag), 53\% 
(two lags), and 61\% (three lags) of the parameters, thus outperforming BMA. In the inflation simulations, the percentages are somewhat lower: 39\% (one lag), 59\% (two lags), and 48\% (three lags). Hence, a slight advantage for WALS over BMA.

The above estimation simulations were based on the assumption that the data-generation process and the model coincide. For example, if the DGP has one lag, then we use a model with one lag. This, of course, is not realistic, since in practice we don't know the DGP and therefore the chance that our chosen model happens to be the DGP is negligible. We now consider one case where the model is underspecified. More specifically, the DGP has three lags, but the model has only one lag. We estimate the parameters in the one-lag model and compare with the corresponding (true) parameters in the three-lag DGP. The results are presented in Table 7.13. Here, also, WALS appears to be at an advantage. For 88\% (growth) and $61 \%$ (inflation) of the parameters, WALS achieves a lower RMSE than BMA.

\begin{tabular}{llllll}
\hline \hline & Growth & & & Inflation \\
\hline & WALS & BMA & & WALS & BMA \\
Intercept & 0.0297 & 0.0302 & Intercept & 0.0520 & 0.0513 \\
G $_{t-1}$ & 0.0201 & 0.0202 & INF $_{t-1}$ & 0.0442 & 0.0437 \\
Invest $_{t-1}$ & 0.0356 & 0.0357 & Ex_rate $_{t-1}$ & 0.0154 & 0.0153 \\
ImpExp $_{t-1}$ & 0.0131 & 0.0132 & Pr_index $_{t-1}$ & 0.0297 & 0.0297 \\
Nat_acc $_{t-1}$ & 0.0181 & 0.0182 & Hfood_pr $_{t-1}$ & 0.0263 & 0.0264 \\
Mon_agg $_{t-1}$ & 0.0175 & 0.0223 & Int_rate $_{t-1}$ & 0.0107 & 0.0127 \\
Pr_index $_{t-1}$ & 0.0103 & 0.0121 & Credit $_{t-1}$ & 0.0101 & 0.0123 \\
Gstar $_{t-1}$ & 0.0162 & 0.0121 & Nat_acc $_{t-1}$ & 0.0167 & 0.0188 \\
& & & Gstar $_{t-1}$ & 0.0107 & 0.0115 \\
\hline \hline
\end{tabular}

Table 7.13 RMSE for estimation simulations in the case of misspecification, Models 1 and 2, Version 2.

\section{A FORECAST EXPERIMENT}

We conduct a second experiment, this time in forecasting rather than estimation. Suppose we use $T_{1}<T=42$ quarters on which we base our estimates. This leaves us $T_{2}=T-T_{1}>0$ quarters for forecast experiments. The h-period forecast is given by

$$
\hat{y}_{T_{1}+h}=\hat{\alpha}(L) y_{T_{1}+h-1}+\hat{\gamma}(L) f_{T_{1}+h-1} \quad\left(h=1, \ldots, T_{2}\right),
$$

where $y$ denotes either GDP growth or inflation. In a practical situation we would not know $f_{T 1+h-1}$ and $y_{T 1+h-1}$, when $h \geq 2$. So we would have to forecast these as well. In the experiment we use the observed values of $f_{T 1+h-1}$ and $y_{T 1+h-1}$, hence not the forecasted value $\hat{y}_{T 1+h-1}$ when $h \geq 2$. Then we compute

$$
\mathrm{RMSE}_{T_{1}}=\sqrt{\frac{1}{T-T_{1}} \sum_{h=1}^{T-T_{1}}\left(\hat{y}_{T_{1}+h}-y_{T_{1}+h}\right)^{2}},
$$

which depends on the estimation period $T_{1}$, the model, and the method (BMA or WALS). The results are presented in Tables 8.14 and 8.15.

In this case we have calculated the RMSE not only for BMA and WALS, but also for two traditional methods of estimation: general-to-specific (GtS) model selection followed by estimation of the selected model, and ordinary least squares (OLS) of the unrestricted model. Including these standard forecasting methods allows us to compare model averaging with more traditional methods.

For all cases, the smaller is the estimation period $T_{1}$, the less accurate are the estimates and the forecasts, that is, the RMSE increases as $T_{1}$ decreases. This is to be expected and it happens most of the time, but not always. In particular the behavior for $T_{1}=35$ is different. 
The explanation lies in the global financial crisis, which affected Armenia heavily. From the third quarter of 2008 (quarter 34 in our data set) to the second quarter of 2009 (quarter 37) Armenia's GDP decreased by 18\%. The largest decrease (around 9.0\%) in real GDP took place in the fourth quarter of 2008 (quarter 35). Such a large decrease in real GDP causes a large deviation of real GDP from its long-term trend, and this explains (in part) why the RMSE values calculated for $T_{1}=35$ are relatively large, and for $T_{1}=36$ somewhat smaller.

\begin{tabular}{|c|c|c|c|c|c|c|c|}
\hline Number of lags & Version & Method & 38 & 37 & $\begin{array}{l}T_{1} \\
36\end{array}$ & 35 & 34 \\
\hline \multirow[t]{8}{*}{ One lag } & \multirow[t]{4}{*}{1} & WALS & 0.8557 & 0.9967 & 2.5503 & 6.1158 & 3.6533 \\
\hline & & BMA & 0.8338 & 0.9726 & 2.4993 & 6.3675 & 3.5549 \\
\hline & & $\mathrm{GtS}$ & 0.9606 & 1.1124 & 2.6739 & 6.0492 & 3.4711 \\
\hline & & OLS & 0.9847 & 1.0726 & 3.2020 & 5.6782 & 3.6570 \\
\hline & \multirow[t]{4}{*}{2} & WALS & 0.8597 & 1.0181 & 2.8576 & 5.8070 & 3.6330 \\
\hline & & BMA & 0.9416 & 1.1265 & 2.5818 & 5.9392 & 3.6009 \\
\hline & & GtS & 1.1311 & 1.2979 & 2.3720 & 6.0667 & 3.5998 \\
\hline & & OLS & 0.9847 & 1.0726 & 3.2020 & 5.6782 & 3.6570 \\
\hline \multirow[t]{8}{*}{ Two lags } & \multirow[t]{4}{*}{1} & WALS & 2.2203 & 2.8415 & 3.6176 & 2.7037 & 2.6341 \\
\hline & & BMA & 1.8333 & 2.3204 & 3.2558 & 2.4816 & 1.7849 \\
\hline & & $\mathrm{GtS}$ & 2.0147 & 2.9072 & 3.1916 & 2.4471 & 1.5800 \\
\hline & & OLS & 2.6610 & 3.3104 & 3.5279 & 3.2889 & 3.2062 \\
\hline & \multirow[t]{4}{*}{2} & WALS & 2.2162 & 2.8118 & 3.5271 & 3.1048 & 2.7043 \\
\hline & & BMA & 2.2155 & 2.6711 & 3.6429 & 3.0343 & 2.5689 \\
\hline & & $\mathrm{GtS}$ & 2.9367 & 3.4904 & 3.7139 & 3.1051 & 2.8986 \\
\hline & & OLS & 2.6610 & 3.3104 & 3.5279 & 3.2889 & 3.2062 \\
\hline \multirow[t]{8}{*}{ Three lags } & \multirow[t]{4}{*}{1} & WALS & 2.3276 & 2.5872 & 4.3087 & 4.5578 & 2.8051 \\
\hline & & BMA & 2.1199 & 1.9616 & 3.2988 & 3.8783 & 3.0844 \\
\hline & & $\mathrm{GtS}$ & 2.0535 & 2.5983 & 4.1221 & 4.5073 & 3.5460 \\
\hline & & OLS & 2.5757 & 3.1871 & 4.4612 & 4.9230 & 3.1832 \\
\hline & \multirow[t]{4}{*}{2} & WALS & 2.2043 & 2.7098 & 4.1208 & 4.6082 & 3.2474 \\
\hline & & BMA & 2.1169 & 2.8038 & 4.2715 & 4.6699 & 3.6258 \\
\hline & & $\mathrm{GtS}$ & 2.8060 & 1.5199 & 3.8202 & 4.4603 & 4.3567 \\
\hline & & OLS & 2.5757 & 3.1871 & 4.4612 & 4.9230 & 3.1832 \\
\hline
\end{tabular}

Table 8.14 RMSE for ex-post forecast accuracy, Model 1 (Growth).

Two main conclusions emerge from Tables 8.14 and 8.15. First, we see that the model averaging techniques WALS and BMA outperform the more traditional methods GtS and OLS. But the choice between WALS and BMA is still ambiguous. While in the estimation simulations we found that WALS performs better than BMA, we find in the forecasting simulations that BMA performs better than WALS in 2/3 of the 30 forecasts, both for growth and for inflation.

\section{CONCLUDING REMARKS}

We have applied two alternative model averaging algorithms (WALS and BMA) to the problem of estimating factor-based dynamic models in Armenia. The same models are also used to forecast two key macroeconomic variables, namely real GDP growth and inflation. The theoretical advantage of using model averaging is that it allows all models to play a role in the estimation and forecasting, thus avoiding the problem of pretesting. A comparison of the WALS to the BMA algorithm does not reveal large differences in performance. The WALS methodology has a stronger theoretical appeal, but - in the current context - there is not sufficient evidence to prefer one over the other. The simulations do show, however, that both model averaging methods outperform the more traditional methods (general-to-specific and OLS). 


\begin{tabular}{|c|c|c|c|c|c|c|c|}
\hline Number of lags & Version & Method & 38 & 37 & $\begin{array}{l}T_{1} \\
36 \\
\end{array}$ & 35 & 34 \\
\hline \multirow[t]{8}{*}{ One lag } & \multirow[t]{4}{*}{1} & WALS & 0.8542 & 0.7807 & 0.9050 & 0.8545 & 0.8993 \\
\hline & & BMA & 0.8851 & 0.8810 & 0.9949 & 0.9373 & 0.9697 \\
\hline & & $\mathrm{GtS}$ & 0.9906 & 1.0484 & 1.0819 & 1.0232 & 1.0198 \\
\hline & & OLS & 0.9060 & 0.8448 & 0.8741 & 0.8788 & 0.8842 \\
\hline & \multirow[t]{4}{*}{2} & WALS & 0.8923 & 0.8061 & 0.9000 & 0.8813 & 0.8865 \\
\hline & & BMA & 0.9579 & 0.8718 & 0.9787 & 0.9291 & 0.9421 \\
\hline & & $\mathrm{GtS}$ & 1.0024 & 0.9252 & 1.0051 & 0.9481 & 0.9559 \\
\hline & & OLS & 0.9060 & 0.8448 & 0.8741 & 0.8788 & 0.8842 \\
\hline \multirow[t]{8}{*}{ Two lags } & \multirow[t]{4}{*}{1} & WALS & 1.6452 & 1.6568 & 1.5987 & 1.7970 & 1.5262 \\
\hline & & BMA & 1.0726 & 0.9829 & 0.8997 & 1.0536 & 0.9385 \\
\hline & & $\mathrm{GtS}$ & 1.0536 & 0.9371 & 0.7445 & 1.0959 & 0.8920 \\
\hline & & OLS & 2.0139 & 2.1006 & 2.0722 & 2.3070 & 1.8852 \\
\hline & \multirow[t]{4}{*}{2} & WALS & 1.6357 & 1.6463 & 1.5935 & 1.7557 & 1.5967 \\
\hline & & BMA & 1.1079 & 1.0094 & 1.0292 & 1.1293 & 1.3293 \\
\hline & & $\mathrm{GtS}$ & 1.0076 & 0.9035 & 1.0614 & 1.1510 & 1.2761 \\
\hline & & OLS & 2.0139 & 2.1006 & 2.0722 & 2.3070 & 1.8852 \\
\hline \multirow[t]{8}{*}{ Three lags } & \multirow[t]{4}{*}{1} & WALS & 4.5016 & 3.8276 & 4.1335 & 3.9527 & 2.7138 \\
\hline & & BMA & 1.2269 & 1.1040 & 1.0326 & 0.9662 & 1.1329 \\
\hline & & $\mathrm{GtS}$ & 6.1520 & 1.1017 & 4.7159 & 4.7402 & 4.5196 \\
\hline & & OLS & 6.1409 & 5.2268 & 5.7689 & 5.4534 & 3.5626 \\
\hline & \multirow[t]{4}{*}{2} & WALS & 4.2447 & 3.4789 & 3.9977 & 3.8076 & 2.4278 \\
\hline & & BMA & 1.3646 & 1.2628 & 1.3900 & 1.2499 & 1.9155 \\
\hline & & $\mathrm{GtS}$ & 0.9806 & 1.0851 & 2.0882 & 1.9551 & 1.7758 \\
\hline & & OLS & 6.1409 & 5.2268 & 5.7689 & 5.4534 & 3.5626 \\
\hline
\end{tabular}

Table 8.15 RMSE for ex-post forecast accuracy, Model 2 (Inflation).

\section{REFERENCES}

Bernanke, B.S., J. Boivin and P. Eliasz (2005). Measuring the effects of monetary policy: A factor-augmented vector autoregressive (FAVAR) approach. Quarterly Journal of Economics, 120, 387-422.

Danilov, D. and J.R. Magnus (2004). On the harm that ignoring pretesting can cause. Journal of Econometrics, 122, 27-46.

De Luca, G. and J.R. Magnus (2011). Bayesian model averaging and weighted average least squares: Equivariance, stability, and numerical issues. The Stata Journal, 11, 518-544.

Forni, M., M. Hallin, M. Lippi and L. Reichlin (2000). The generalized dynamic-factor model: Identification and estimation. The Review of Economics and Statistics, 82, 540554.

Forni, M., M. Hallin, M. Lippi and L. Reichlin (2003). Do financial variables help forecasting inflation and real activity in the euro area. Journal of Monetary Economics, 50, 12431255.

Koop, G. and S. Potter (2004). Forecasting in dynamic factor models using Bayesian model averaging. The Econometrics Journal, 7, 550-565.

Magnus, J.R. and J. Durbin (1999). Estimation of regression coefficients of interest when other regression coefficients are of no interest. Econometrica, 67, 639-643. 
Magnus, J.R., O. Powell and P. Prüfer (2010). A comparison of two model averaging techniques with an application to growth empirics. Journal of Econometrics, 154, 139153.

Magnus, J.R., A.T.K. Wan and X. Zhang (2011). Weighted average least squares estimation with nonspherical disturbances and an application to the Hong Kong housing market. Computational Statistics \& Data Analysis, 55, 1331-1341.

Mann, H.B. and A. Wald (1943). On the statistical treatment of linear stochastic difference equations. Econometrica, 11, 173-220.

Stock, J.H. and M.W. Watson (2002). Macroeconomic forecasting using diffusion indexes. Journal of Business \& Economic Statistics, 20, 147-162.

Zellner, A. (1986). On assessing prior distributions and Bayesian regression analysis with gprior distributions. In Bayesian Inference and Decision Techniques: Essays in Honor of Bruno de Finetti, ed. P.K. Goel and A. Zellner. Amsterdam: North-Holland, 233-243. 